\title{
Cost-effectiveness Analysis of Rivaroxaban in the Secondary Prevention of Acute Coronary Syndromes in Sweden
}

\author{
Najida Begum · Stephanie Stephens · Olaf Schoeman • \\ Anina Fraschke · Bodo Kirsch · Jean-Baptiste Briere - Freek W. A. Verheugt • \\ Ben A. van Hout
}

To view enhanced content go to www.cardiologytherapy-open.com

Received: March 12, 2015 / Published online: June 23, 2015

(c) The Author(s) 2015. This article is published with open access at Springerlink.com

\section{ABSTRACT}

Background: Worldwide, coronary heart disease accounts for 7 million deaths each year. In Sweden, acute coronary syndrome (ACS) is a leading cause of hospitalization and is responsible for 1 in 4 deaths.

Objective: The aim of this analysis was to assess the cost-effectiveness of rivaroxaban $2.5 \mathrm{mg}$

Electronic supplementary material The online version of this article (doi:10.1007/s40119-015-0041-3) contains supplementary material, which is available to authorized users.

N. Begum · S. Stephens $(\varangle) \cdot$ B. A. van Hout Pharmerit Ltd, Enterprise House, Innovation Way, Heslington, York YO10 5NQ, UK

e-mail: sstephens@pharmerit.com

O. Schoeman

Pharmerit GmbH, Berlin, Germany

A. Fraschke

Bayer AB, Solna, Sweden

B. Kirsch · J.-B. Briere

Bayer Pharma AG, Berlin, Germany

F. W. A. Verheugt

University Medical Center St. Radboud, Nijmegen,

The Netherlands

B. A. van Hout

University of Sheffield, School of Health and Related

Research, Sheffield, UK twice daily (BID) in combination with standard antiplatelet therapy (ST-APT) versus ST-APT alone, for the secondary prevention of ACS in adult patients with elevated cardiac biomarkers without a prior history of stroke/transient ischemic attack (TIA), from a Swedish societal perspective, based on clinical data from the global ATLAS ACS 2-TIMI 51 trial, literature-based quality of life data and costs sourced from Swedish national databases.

Methods: A Markov model was developed to capture rates of single and multiple myocardial infarction (MI), ischemic and hemorrhagic stroke, thrombolysis in myocardial infarction (TIMI) major, minor, and "requiring medical attention" bleeds, revascularization events, and associated costs and utilities in patients who were stabilized after an initial ACS event. Efficacy and safety data for the first 2 years came from the ATLAS ACS 2-TIMI 51 trial. Long-term probabilities were extrapolated using safety and effectiveness of acetylsalicylic acid data, which was estimated from published literature, assuming constant rates in time. Future cost and effects were discounted at $3.0 \%$. Univariate and probabilistic sensitivity analyses were conducted. 
Results: In the base case, the use of rivaroxaban $2.5 \mathrm{mg}$ BID was associated with improvements in survival and quality-adjusted life years (QALYs), yielding an incremental cost per QALY of 71,246 Swedish Krona (SEK) (€8045). The outcomes were robust to changes in inputs. The probabilistic sensitivity analysis demonstrated rivaroxaban $2.5 \mathrm{mg}$ BID to be cost-effective in $>99.9 \%$ of cases, assuming a willingness-to-pay threshold of SEK 500,000 $(€ 56,458)$.

Conclusion: Compared with ST-APT alone, the use of rivaroxaban $2.5 \mathrm{mg}$ BID in combination with ST-APT can be considered a cost-effective treatment option for ACS patients with elevated cardiac biomarkers without a prior history of stroke/TIA in Sweden.

Funding: Bayer Pharma AG.

$\begin{array}{llr}\text { Keywords: Acute } & \text { coronary } & \text { syndrome; } \\ \text { Antiplatelet; } & \text { Antithrombotic; } & \text { Cost- } \\ \text { effectiveness; } & \text { Rivaroxaban; } & \text { Secondary } \\ \text { prevention } & & \end{array}$

\section{INTRODUCTION}

Coronary heart disease (CHD) is a major public health concern; it is the leading cause of mortality worldwide, accounting for more than 7 million deaths each year [1]. The majority of CHD-related deaths are due to acute coronary syndrome (ACS) or resulting complications [2, 3]. In Sweden, 1 in 4 deaths are estimated to be due to ACS [4]. ACS is based on the underlying pathophysiology of thrombosis, which is induced by the rupture or erosion of vulnerable coronary plaque. Such a rupture will cause the formation of a blood clot, which subsequently blocks the artery, leading to a sudden or substantial reduction in the coronary blood flow. Manifestations of ACS typically fall into three categories: ST-segment elevation myocardial infarction (STEMI), nonST-segment elevation myocardial infarction (NSTEMI) and unstable angina (UA). All three are associated with a (very) high, moderate and (very) low degree of obstruction to myocardial perfusion and severity of myocardial ischemia, respectively. Electrocardiograms (ECGs) and cardiac biomarkers (e.g., troponin) can be used to differentiate between the types of ACS (i.e., between [N]STEMI and UA) and these play a crucial role in risk stratification because biomarker elevation can help to identify myocardial cellular damage and potentially predict short-term outcomes of subsequent myocardial infarction (MI) and death $[5,6]$.

Current European guidelines recommend dual antiplatelet therapy of acetylsalicylic acid (ASA) plus a $\mathrm{P}_{2} \mathrm{Y}_{12}$ inhibitor (i.e., ticagrelor, prasugrel, ticlopidine or clopidogrel) to reduce the risk of thrombus formation in ACS patients $[7,8]$. Dual antiplatelet therapy has proven efficacy in reducing the likelihood of secondary cardiovascular (CV) events, with an increase in the rate of major bleeding [8]. Despite such 'dual antiplatelet' prophylaxis, $20 \%$ of patients die within 5 years of an ACS event. The vast majority of these deaths occur after discharge from hospital for the initial ACS event (the index event) $[5,9]$. To further reduce this burden, several novel oral anticoagulants (apixaban, dabigatran and rivaroxaban) have been investigated for the prevention of secondary events in the ACS indication $[8,10,11]$.

The Anti-Xa Therapy to Lower Cardiovascular Events in Addition to Standard Therapy in Subjects with Acute Coronary Syndrome 2-Thrombolysis in Myocardial Infarction 51 (ATLAS ACS 2-TIMI 51) trial (Clinicaltrials.gov identifier: NCT00809965) was a global multicenter, randomized, doubleblind, placebo-controlled, event-driven study. 
The design and clinical results have been reported elsewhere [11]. The trial randomized 15,526 patients with a recent ACS event to receive twice-daily (BID) doses of $2.5 \mathrm{mg}$ or $5 \mathrm{mg}$ rivaroxaban in combination with standard antiplatelet therapy (ST-APT), defined as acetylsalicylic acid (ASA) alone or ASA in combination with clopidogrel or ticlopidine, versus ST-APT alone. Rivaroxaban $2.5 \mathrm{mg}$ BID in combination with ST-APT was shown to reduce the risk of the composite endpoint of death from CV causes, MI or stroke (hazard ratio $[\mathrm{HR}]=0.84 ; \quad 95 \%$ confidence interval [CI] $0.72-0.97)$; the risk reduction in all-cause mortality $(\mathrm{HR}=0.68 ; 95 \%$ CI $0.53-0.87$ ) was achieved without an increase in the risk of fatal bleeding ( $\mathrm{HR}=0.67 ; 95 \%$ CI 0.24-1.89) [11].

Rivaroxaban $2.5 \mathrm{mg}$ BID has marketing approval in Europe for an adult post-ACS patient population with elevated cardiac biomarkers and without a prior history of stroke or transient ischemic attack (TIA). The aim of this research was to estimate the costeffectiveness of rivaroxaban $2.5 \mathrm{mg}$ BID when used as secondary prevention versus ST-APT alone in such patients, from a Swedish societal perspective.

\section{METHODS}

The current study consists of a costeffectiveness analysis (CEA) of secondary prevention in adult ACS patients with elevated cardiac biomarkers without a prior history of stroke or TIA. This article is based on previously conducted studies and does not involve any new studies of human or animal subjects performed by any of the authors.

Patients enter the model following stabilization of their ACS event which is defined according to the ATLAS ACS-TIMI 51 study as the time, up to 7 calendar days after the subject has been hospitalized for the index ACS event, when the initial inpatient treatment (including revascularization procedures and parenteral anticoagulant therapy) would have been discontinued. To inform the design of the model and specify model inputs, formal systematic literature reviews of economic evaluations, clinical data from epidemiological studies and clinical trials, quality of life data, and costs and resource use were performed according to published guidelines [12, 13]. The searches encompassed, among other sources, electronic medical databases commonly prescribed by HTA authorities (Medline, Medline in-process, Embase, EconLit, National Health Service Economic Evaluation Database, Health Technology Assessment Database, and Cochrane Library [CENTRAL and database of systematic reviews]), and conference proceedings of most important cardiovascular and health economic conferences (American Heart Association [AHA], European Society of Cardiology [ESC], American College of Cardiology [ACC], American College of Chest Physicians [ACCP] and International Society for Pharmacoeconomics and Outcomes Research [ISPOR]). The full details of the literature review are provided in the online appendix to this article on the publisher's website.

Clinical event risks, safety and treatment discontinuation rates from the ATLAS ACS 2-TIMI 51 trial, combined with real-world evidence to estimate event rates beyond the trial period, were used to evaluate the long-term cost-effectiveness of treating patients with rivaroxaban $2.5 \mathrm{mg}$ BID in combination with ST-APT. The clinical data, used to inform the first 2 years of the model, were estimated from the intent-to-treat (ITT) trial population, comprising adult patients with elevated cardiac 
biomarkers without a prior history of stroke or TIA, which represents the European label for rivaroxaban. A maximum treatment duration of 2 years was assumed for rivaroxaban $2.5 \mathrm{mg}$ BID in the analysis. To comply with current clinical guidelines for ACS, the maximum treatment duration for clopidogrel or ticlopidine in both arms of the analysis was 1 year $[7,8]$.

\section{Model Structure}

With consideration of ESC guidelines [8], a Markov model was constructed to assess the cost-effectiveness of rivaroxaban $2.5 \mathrm{mg}$ BID in combination with ST-APT versus ST-APT alone. The underlying model structure applied was similar in design to previously published economic evaluations in ACS and wider CV disease [14-17].

The Markov model was constructed in Microsoft Excel 2010 with a 40-year (i.e., lifetime) horizon to simulate the costs and benefits of rivaroxaban $2.5 \mathrm{mg}$ BID treatment in combination with ST-APT. The model considered a patient cohort with an average age of 62 years, to replicate the average age of patients with elevated biomarkers without a prior history of stroke or TIA in the ATLAS ACS 2-TIMI 51 trial.

The model consisted of 16 health states which represent the occurrence of single and multiple cardiovascular events over time (Fig. 1). Health states separately describing MI, ischemic stroke (IS), hemorrhagic stroke/

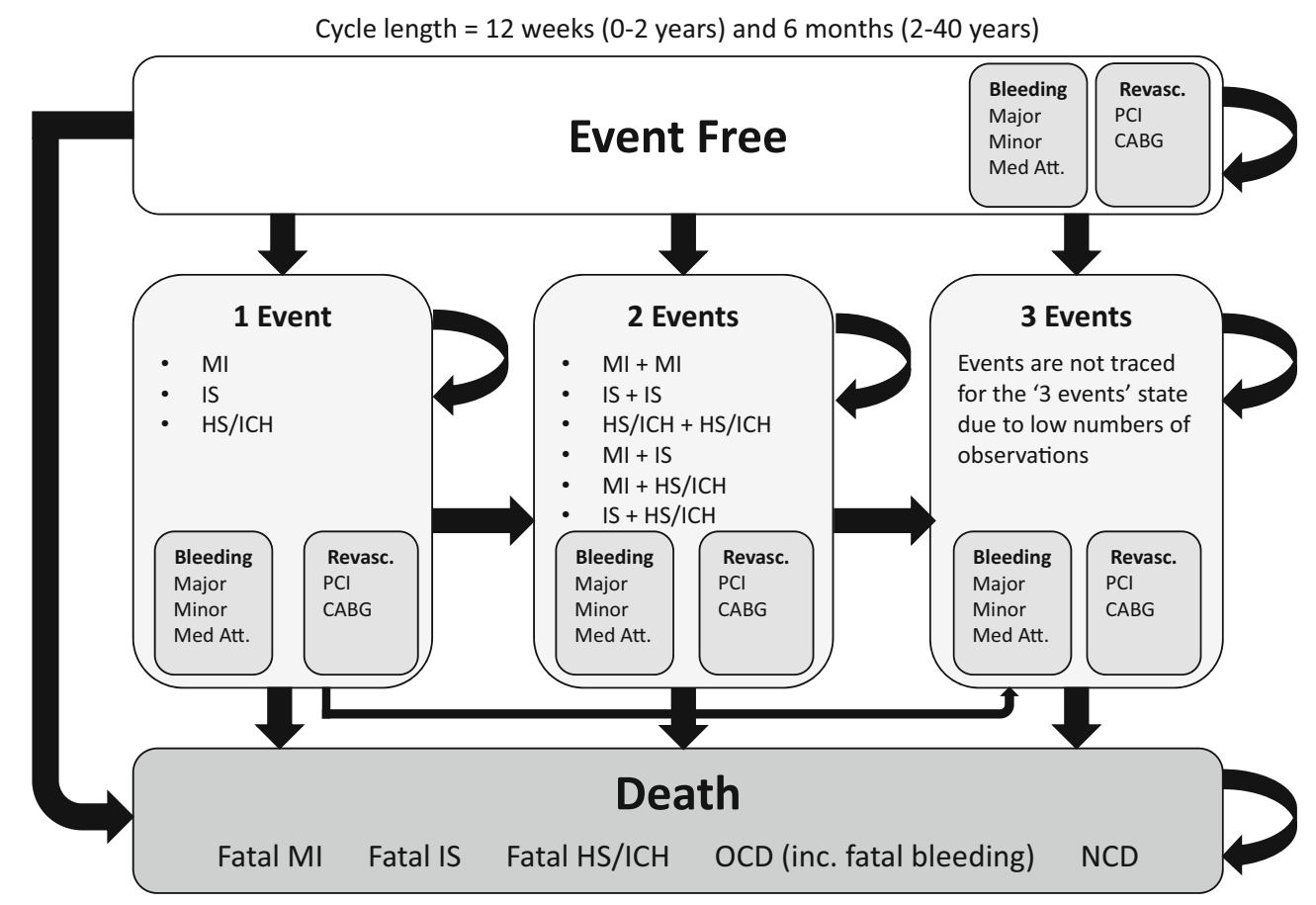

Fig. 1 Markov model structure showing 16 health states; bleedings and revascularizations were considered as transient health states with a one-off cost and short-term disutility impact. $C A B G$ coronary artery bypass graft, $H S$ hemorrhagic stroke, ICH intracranial hemorrhage, Incl. including, $I S$ ischemic stroke, $M I$ myocardial infarction, Med Att. medical attention, NCD non-cardiovascular death, $O C D$ other cardiovascular death, $P C I$ percutaneous coronary intervention 
intracranial hemorrhage (HS/ICH), and death define the model framework. These are key events that a patient might experience after an ACS. Within each of the non-fatal event states there are tunnel states representing the time since the event. These allow for variable transition probabilities, costs and utility decrements following a cardiovascular event $[11,18,19]$. Fatal events in the model, although grouped together in the final outcome, consider fatal MI, fatal IS, fatal HS/ $\mathrm{ICH}$, other $\mathrm{CV}$ death and non-CV death as distinct events in terms of event probabilities and costs. Fatal bleeding events are considered within the 'other $\mathrm{CV}$ death' health state and ICHs are captured in the ' $\mathrm{HS} / \mathrm{ICH}^{\prime}$ health state. Other non-fatal bleeds, including thrombolysis in myocardial infarction (TIMI) major, TIMI minor and TIMI requiring medical attention bleeding events, are associated with a one-off cost and short-term disutility, and were thus considered transient health states. Percutaneous coronary interventions (PCI) and coronary artery bypass grafts (CABG) were also included as transient health states. All short-term clinical data were taken from the European label population subgroup of ATLAS ACS 2-TIMI 51 trial, that is, patients with elevated biomarkers without a prior history of stroke/TIA. Clinical results for this population have been published elsewhere [20]. A full and detailed description of each health state, and how patients may transition between these, is provided in Table 1.

The model considered 12 weekly cycles in the first 2 years (observation period) in line with study visits in ATLAS ACS 2-TIMI 51, and 6 monthly cycles thereafter (extrapolation period), to allow for variable transition probabilities, costs and utilities as patients recover from the initial event and their risk of secondary events decreases [21]. A half-cycle correction was applied to reflect the continuous nature of the occurrence of transitions during each cycle by assuming that, on average, all transitions occur halfway through any particular cycle. At the end of each model cycle, patients remained in their current health state, experienced a subsequent $\mathrm{CV}$ event or died. After an event, patients accrued additional costs and utility decrements in subsequent cycles until they transitioned to a new health state. The model distinguished between three phases within each non-fatal health state: a period comprising the first 6 months after the event, a period comprising the second 6 months after the event, and subsequent 6-month periods (post 12 months). Therefore, the first two phases were incorporated as tunnel states in which patients can remain for one (6-month) cycle only.

\section{Model Assumptions}

The model assumed there was no treatment effect associated with rivaroxaban or clopidogrel or ticlopidine after treatment discontinuation. In line with treatment guidelines, ASA monotherapy was assumed to be continued after discontinuation of all other treatment(s) for the remainder of the model. Rivaroxaban was assumed to be prescribed for a maximum of 2 years. Clopidogrel and ticlopidine were assumed to be discontinued in both treatment arms after 1 year. As ticlopidine is not available in Sweden for the treatment of ACS patients, it was assumed that all patients who received ticlopidine in the ATLAS ACS 2-TIMI 51 clinical trial $(<1 \%$ of patients) were subsequently treated with clopidogrel, without affecting the overall clinical outcomes.

Different assumptions regarding post-event treatment discontinuation rates were applied to 
the first 12 months and subsequent 12 months of the modeled time period.

- Discontinuations of rivaroxaban and/or clopidogrel or ticlopidine for the first year were reflective of the discontinuation rates observed in the clinical trial.

- Based on expert opinion, rivaroxaban discontinuation in the second year of treatment is predicted to be higher in reallife practice than observed in the clinical study.

- During the second year of treatment, an overall discontinuation rate of $81 \%$ was assumed. Efficacy and treatment costs for rivaroxaban in the second year of the model were adjusted accordingly. This assumption is conservative and reflective of the informed decision about therapy physicians make in the second year of treatment.

Revascularization and non-ICH bleeding events were assumed to only occur during the observation period (in accordance with the specified length of treatment in each arm) as the rates would be considered equal after rivaroxaban and ST-APT discontinuation, and their impact on the incremental outcomes negligible after the observation period. The disutility associated with these events does not exceed one model cycle length (12 weeks) and were therefore not modeled as separate health states.

\section{Model Setting}

The CEA was performed from a Swedish societal perspective. The model was run for 40 years after which less than $1 \%$ of patients were still alive (lifetime horizon). All future costs and health outcomes were discounted at a rate of $3.0 \%$ per year, as recommended by the Swedish guidelines for economic evaluations [22]. Costs were expressed in Swedish Krona (SEK) at 2013 prices using the Consumer Price Index (CPI) to inflate costs where relevant [23]. Direct costs were captured in the form of direct medical costs related to antithrombotic treatment and secondary events. Indirect costs were captured in the form of productivity losses and costs of additional life years, constituting a conservative approach given the age of patients in the model [24-27]. All costs were also expressed in Euros $(€ 1=$ SEK 8.8561 , exchange rate taken on January 3, 2014) using foreign exchange rates taken from the European Central Bank (ECB) [28].

\section{Transition Probabilities}

Clinical data from the ATLAS ACS 2-TIMI 51 trial in adults with elevated cardiac biomarkers without a prior history of stroke/TIA show a statistically significant reduction in the combined primary endpoint of $\mathrm{CV}$ death, MI or stroke, with rivaroxaban $2.5 \mathrm{mg}$ twice daily versus placebo $\quad(\mathrm{HR}=0.80, \quad 95 \%$ $\mathrm{CI}=0.68-0.94)$. These data have been reported elsewhere [20]. Patient-level data considering each event type separately were used to estimate transition probabilities for the model. In doing so, both clinical benefits (such as are seen in the case of MIs) and increased risks of events (such as with $\mathrm{HS} / \mathrm{ICH}$ events) are appropriately modeled. The data were interpolated using a parametric, Weibull-based survival analysis to generate consistent cycle-dependent transition probabilities, adjusting for potentially distorting patient drop-out as observed in the trial (i.e., survival progression after an event within the later trial observations was not considered truly reflective of real-world survival due to low patient numbers comprising those later trial observations, thereby resulting in inconsistent estimates for 
Table 1 Description of model health states

\begin{tabular}{|c|c|c|}
\hline Health state & Description & Transitions possible from this health state \\
\hline $\begin{array}{l}\text { Free of secondary events } \\
\text { following index ACS } \\
\text { event ("event-free") }\end{array}$ & $\begin{array}{l}\text { Patients in this health state have not experienced a } \\
\text { secondary cardiovascular event. During each cycle } \\
\text { patients in this health state are at a risk of a non- } \\
\text { fatal or fatal event, or a combination of events }\end{array}$ & $\begin{array}{l}\text { Patients may transition to any other health state } \\
\text { from here }\end{array}$ \\
\hline Non-fatal MI & $\begin{array}{l}\text { Patients enter this health state if their first secondary } \\
\text { event (i.e., their first event following their index } \\
\text { ACS event) is a non-fatal MI. Within this health } \\
\text { state are tunnel states depending on the time since } \\
\text { the non-fatal MI occurred. When patients enter the }\end{array}$ & $\begin{array}{l}\text { Patients may transition to any of the following health } \\
\text { states from the non-fatal MI state, regardless of the } \\
\text { time since the MI: two MIs, MI + IS, MI + HS/ } \\
\text { ICH, } 3 \text { events, fatal MI, fatal IS, fatal HS/ICH, } \\
\text { other CV death, or non-CV death }\end{array}$ \\
\hline
\end{tabular}

Non-fatal IS

Non-fatal HS/ICH

Non-fatal MI + nonfatal MI

Non-fatal IS + non-fatal IS

Non-fatal HS/
ICH + non-fatal HS/
ICH
non-fatal MI health state they enter the first tunnel state and they remain here until the next model cycle. If the patient experiences no further event in the following cycle they are still within the nonfatal MI state, but they move to the second tunnel state, with risks of further events, costs and utilities associated with the event changing to represent the improvement in patient's health as the time since the event increases. This pattern continues until the patient reaches the third, and last state associated with the event they have experienced. Patients will remain here until they experience another non-fatal or fatal event which would cause them to move health states

Patients enter this health state if their first secondary event is a non-fatal IS. As with the non-fatal MI state described in the above paragraph, there are tunnel states depending on the time since the nonfatal IS occurred

Patients enter this health state if their first secondary event is a non-fatal HS/ICH. Within this health state are tunnel states depending on the time since the non-fatal HS/ICH occurred

This health state contains patients who have experienced two non-fatal MIs since their index event. Within this health state are tunnel states depending on the time since the second non-fatal MI occurred, as described above for the single event states

This health state contains patients who have experienced two non-fatal ISs since their index event. As with the MI + MI state described in the above paragraph, there are tunnel states depending on the time since the second event causing a patient to be in the IS + IS health state occurred

This health state contains patients who have experienced two non-fatal HS/ICHs since their index event. As with the MI + MI and IS + IS states, within this health state are tunnel states depending on the time since the second non-fatal $\mathrm{HS} / \mathrm{ICH}$ occurred
Patients may transition to any of the following health states from the non-fatal IS state, regardless of the time since the event: two ISs, MI + IS, IS + HS/ $\mathrm{ICH}, 3$ events, fatal MI, fatal IS, fatal $\mathrm{HS} / \mathrm{ICH}$, other $\mathrm{CV}$ death, or non-CV death

Patients may transition to any of the following health states from the non-fatal $\mathrm{HS} / \mathrm{ICH}$ state, regardless of the time since the event: two HS/ICHs, $\mathrm{MI}+\mathrm{HS} / \mathrm{ICH}$, IS + HS/ICH, 3 events, fatal MI, fatal IS, fatal HS/ICH, other CV death, or non-CV death

Patients may transition to any of the following health states from the MI + MI health state: 3 events, fatal MI, fatal IS, fatal HS/ICH, other CV death, or non-CV death

Patients may transition to any of the following health states from the IS + IS health state: 3 events, fatal MI, fatal IS, fatal $\mathrm{HS} / \mathrm{ICH}$, other $\mathrm{CV}$ death, or non-CV death

Patients may transition to any of the following health states from the non-fatal $\mathrm{HS} / \mathrm{ICH}+$ non-fatal HS/ICH health state: 3 events, fatal MI, fatal IS, fatal $\mathrm{HS} / \mathrm{ICH}$, other $\mathrm{CV}$ death, or non-CV death 
Table 1 continued

\begin{tabular}{|c|c|c|}
\hline Health state & Description & Transitions possible from this health state \\
\hline $\begin{array}{l}\text { Non-fatal MI + non- } \\
\text { fatal IS }\end{array}$ & $\begin{array}{l}\text { This health state contains patients who have } \\
\text { experienced the combination of a non-fatal MI and } \\
\text { a non-fatal IS since their index event. As with the } \\
\text { health states described above where patients have } \\
\text { experienced two secondary events, there are tunnel } \\
\text { states depending on the time since the second event } \\
\text { causing a patient to be in the MI + IS health state } \\
\text { occurred. The second event may be either the non- } \\
\text { fatal MI or the non-fatal IS, the sequence of events } \\
\text { is not explicitly modeled }\end{array}$ & $\begin{array}{l}\text { Patients may transition to any of the following health } \\
\text { states from the non-fatal MI + non-fatal IS health } \\
\text { state: } 3 \text { events, fatal MI, fatal IS, fatal HS/ICH, } \\
\text { other CV death, or non-CV death }\end{array}$ \\
\hline $\begin{array}{l}\text { Non-fatal MI + non- } \\
\text { fatal HS/ICH }\end{array}$ & $\begin{array}{l}\text { This health state contains patients who have } \\
\text { experienced a non-fatal MI and a non-fatal HS/ } \\
\text { ICH since their index event. As with the health } \\
\text { states described above where patients have } \\
\text { experienced two secondary events, there are tunnel } \\
\text { states depending on the time since the second event } \\
\text { causing a patient to be in the MI + HS/ICH } \\
\text { health state occurred. The second event may be } \\
\text { either the non-fatal MI or the non-fatal HS/ICH, } \\
\text { the sequence of events is not explicitly modeled }\end{array}$ & $\begin{array}{l}\text { Patients may transition to any of the following health } \\
\text { states from the non-fatal MI + non-fatal HS/ICH } \\
\text { health state: } 3 \text { events, fatal MI, fatal IS, fatal HS/ } \\
\text { ICH, other CV death, or non-CV death }\end{array}$ \\
\hline $\begin{array}{l}\text { Non-fatal IS + non-fatal } \\
\text { HS/ICH }\end{array}$ & $\begin{array}{l}\text { This health state contains patients who have } \\
\text { experienced the combination of a non-fatal IS and } \\
\text { a non-fatal HS/ICH since their index event. As } \\
\text { with the health states described above where } \\
\text { patients have experienced two secondary events, } \\
\text { there are tunnel states depending on the time since } \\
\text { the second event causing a patient to be in the } \\
\text { IS + HS/ICH health state occurred. The second } \\
\text { event may be either the non-fatal IS or the non- } \\
\text { fatal HS/ICH, the sequence of events is not } \\
\text { explicitly modeled }\end{array}$ & $\begin{array}{l}\text { Patients may transition to any of the following health } \\
\text { states from the non-fatal IS + non-fatal HS/ICH } \\
\text { health state: } 3 \text { events, fatal MI, fatal IS, fatal HS/ } \\
\text { ICH, other CV death, or non-CV death }\end{array}$ \\
\hline Three events & $\begin{array}{l}\text { Patients in this health state have experienced three } \\
\text { non-fatal events since the index ACS event. The } \\
\text { three events may be any combination of MIs, ISs } \\
\text { and HS/ICHs. Due to the small numbers of } \\
\text { patients who experience three separate non-fatal } \\
\text { events the distinction between the event types is } \\
\text { not made in this health state. However, the } \\
\text { distinction of time periods within this health state } \\
\text { as described for all other non-fatal event health } \\
\text { states above is still considered }\end{array}$ & $\begin{array}{l}\text { Patients may only transition to fatal health states } \\
\text { from the three events state }\end{array}$ \\
\hline Fatal events & $\begin{array}{l}\text { Five fatal event health states (fatal MI, fatal IS, fatal } \\
\text { HS/ICH, other CV death, non-CV death) are } \\
\text { absorbing states. Once a patient enters one of these } \\
5 \text { states they remain there until the end of the } \\
\text { model }\end{array}$ & No transitions possible \\
\hline
\end{tabular}

$A C S$ acute coronary syndrome, $C V$ cardiovascular, $H S$ hemorrhagic stroke, $I C H$ intracranial hemorrhage, $I S$ ischemic stroke, $M I$ myocardial infarction

transition probabilities for the first 2 years of the model). The decision to continue treatment with clopidogrel or ticlopidine in the second year of the ATLAS ACS 2-TIMI 51 trial was at the physician's discretion (reflective of real-life setting). To comply with European Society of 
Cardiology (ESC) guidelines, and accommodate the recommended discontinuation of clopidogrel or ticlopidine after the first year, transition probabilities were adjusted by a factor of $1 / 0.8$. This adjustment factor was based on the relative risk reduction (RRR) for clopidogrel versus ASA demonstrated in the Clopidogrel in Unstable angina to prevent Recurrent Events (CURE) trial [29].

To capture long-term survival rates, transition probabilities on the effectiveness and safety of ASA were extrapolated assuming constant rates in time. The Weibull distribution, chosen to reflect the fact that patient risk decreases over time following a qualifying event, is time dependent and was used to estimate transition probabilities for each 12-week cycle within the observation period. Therefore, an average estimate over multiple cycles in which to base the extrapolation period was not required. The last observation from the control arm of the observation period is used to estimate transition probabilities applied in the extrapolation period, with the RRR calculated from CURE used to model transition probabilities based on ASA monotherapy use in the long term.
Furthermore, event rates applied in the extrapolation period were based on, and corrected for, the increased risk of events due to aging, initial case fatalities and the reduction in relative risk of experiencing subsequent events over time. Swedish life tables provided probabilities of non-CV death for patients aged 62 years (using an elimination method) [30, 31].

In an aging population, patients with ACS are at an increased risk of experiencing subsequent $\mathrm{CV}$ events or developing comorbidities that may contribute to the onset of future events $[6,32]$. The annual age-specific risks of experiencing fatal and non-fatal events were taken from Swedish sources (Table 2). Patients who have experienced an ACS event are at an elevated risk of experiencing a subsequent event, typically within the first 6 months following an event, although this risk diminishes over time [33]. The risk of suffering a second subsequent event after the first is assumed to be 1.5 times the risk of suffering a first subsequent event after the index event [33]. Initial case fatalities (proportion of fatal events typically within 28-30 days of onset) taken from the ATLAS ACS 2-TIMI 51

Table 2 Annual age-specific increased risk of non-fatal and fatal event estimates used to validate the model within the extrapolation period

\begin{tabular}{llll}
\hline Event & \% annual age-specific increase & Confidence interval (\%) & References \\
\hline Non-fatal MI & 5.00 & $2.50-7.50$ & {$[30]$} \\
Non-fatal IS & 9.10 & $4.55-13.65$ & {$[30]$} \\
Non-fatal HS/ICH & 5.90 & $2.95-8.85$ & {$[30]$} \\
Fatal MI & 4.50 & $2.25-6.75$ & {$[30]$} \\
Fatal IS & 3.10 & $1.55-4.65$ & {$[30]$} \\
Fatal HS/ICH & 3.10 & $1.55-4.65$ & (Assumption based on IS) \\
OCD & 6.80 & $3.40-10.20$ & {$[30]$} \\
NCD & 5.60 & $2.80-8.40$ & {$[34]$} \\
\hline
\end{tabular}

$H S$ hemorrhagic stroke, $I C H$ intracranial hemorrhage, $I S$ ischemic stroke, $M I$ myocardial infarction, NCD noncardiovascular death, $O C D$ other cardiovascular death 
clinical trial (MI) and published literature (IS and $\mathrm{HS} / \mathrm{ICH}$ ) were used to define the probability that a patient's first modeled event would result in a fatality [34].

The Sweden MONitoring of trends and determinants In CArdiovascular disease (MONICA) study reported a weighted estimate of median survival after a first MI (based on gender distribution) of 15.82 years [35]. The model was calibrated so that the predicted life expectancy of patients on ST-APT alone after the first MI event was 15.82 years.

\section{Resource Use and Costs}

The cost of non-fatal MI events is estimated based on the mean cost per patient taken from a paper which estimates costs from a Swedish register, accounting for administrative costs, hospitalizations, diagnostic work-ups, interventions and rehabilitation [36]. The proportion of costs allocated to the first 6 months, second 6 months and post 12 month periods following an event were based on those reported by Heeg et al. [21]. Based on Heeg et al.'s findings, $43 \%$ of the total costs of MI are accrued in the first 3 months following the event, $19 \%$ are accrued in the second 3 months, and $38 \%$ are accrued in the remainder of the first year following the event. The cost of non-fatal IS was calculated based on the gender-weighted average costs incurred during an inpatient stay, during outpatient healthcare, and municipal care after a stroke event within the first year [37]. Cost estimates using this information were then applied to the second year after a stroke event. In the absence of specific, separate costs for IS and HS/ICH, the costs were assumed to be the same for the stroke types. Costs for non-fatal/non-ICH bleeding, revascularization and all fatal events (except
non-CV death) were taken from the Socialstyrelsen database [38]. Cost calculations for the transient health states of bleeding and revascularizations were estimated by multiplying the proportion of patients experiencing the event with the unit cost of each procedure/treatment. In the absence of suitable costs for non-CV death, a cost of SEK 0 $(€ 0)$ was assumed. The daily costs for generic clopidogrel, ASA and rivaroxaban, taken from the TLV database, were SEK 1.47 (€0.17), SEK 0.61 (€0.07) and SEK 20.91 (€2.36), respectively; the lowest available prices in February 2013 were used for generic medications [39]. The daily drug price is multiplied by the number of days per model cycle and applied to each living patient within the specified treatment duration (Table 3).

Indirect costs included productivity losses due to the events, calculated using the human capital method (HCM) as prescribed by the Swedish authority [22], and the cost of survival from added life years. The HCM assumes that all productivity loss due to disease can be accounted for as indirect costs and reflects the fact that short-term absence from work due to medical visits as well as due to events of ACS patients lead to (indirect) costs for society. This method is applicable to all patients under the national age of retirement (65 years in Sweden) [40]. The cost of daily productivity loss is given by $\left(\frac{\alpha \times 12}{365}\right) \cdot\left(1+\beta_{1}+\beta_{2}\right)$, where $\alpha$ is the average monthly salary (SEK 29,000) [22], $\beta_{1}$ is the employer benefit (31.42\%) [26] and $\beta_{2}$ is the union benefit (10\%) [26]. The resulting daily cost of SEK 1388 ( $€ 152)$ is then multiplied by the number of days of productivity loss assumed per event (Table 4). The cost of added life years takes into account the difference between consumption and production for patients of each modeled age category (Table 5). The costs 


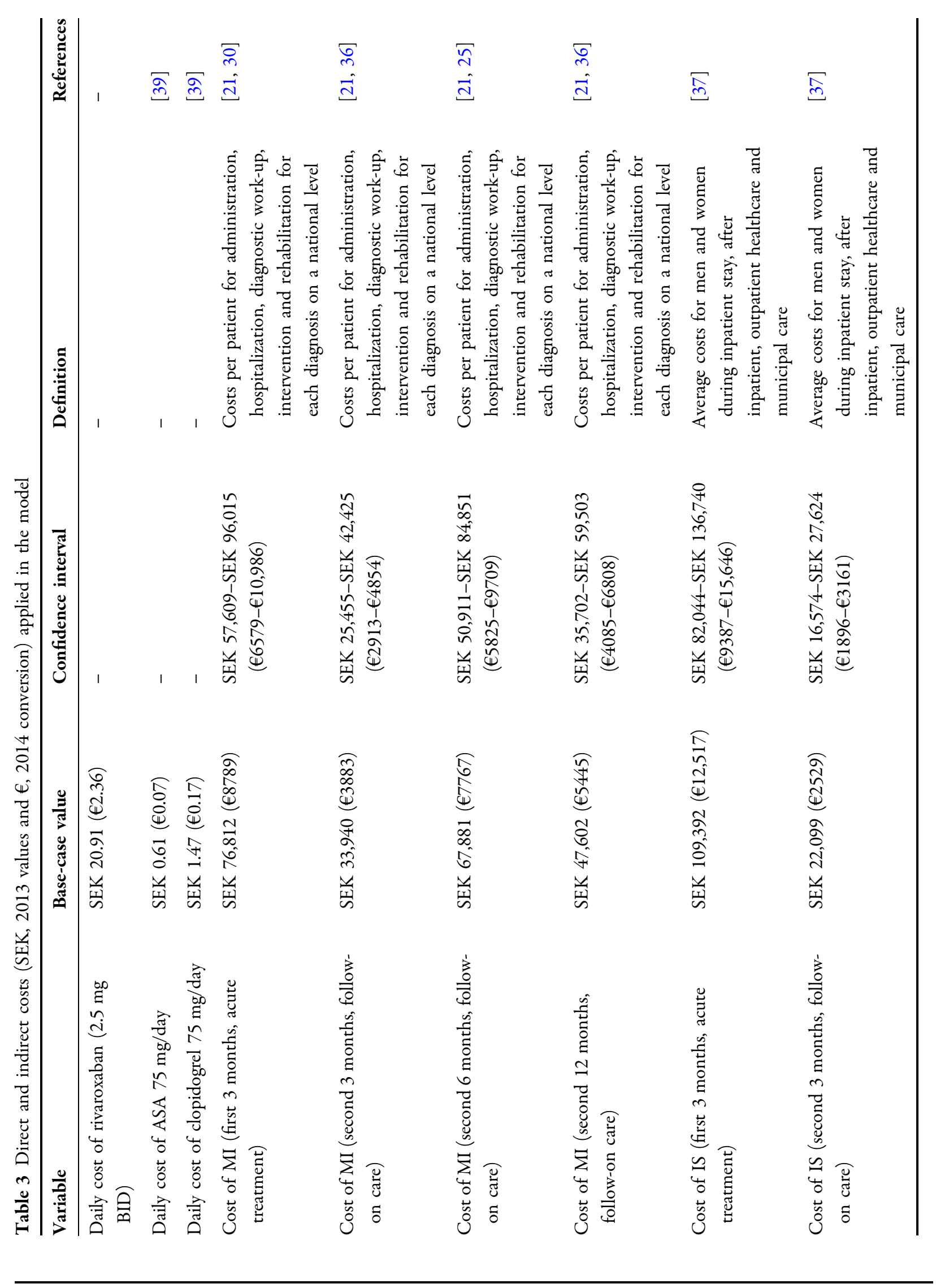




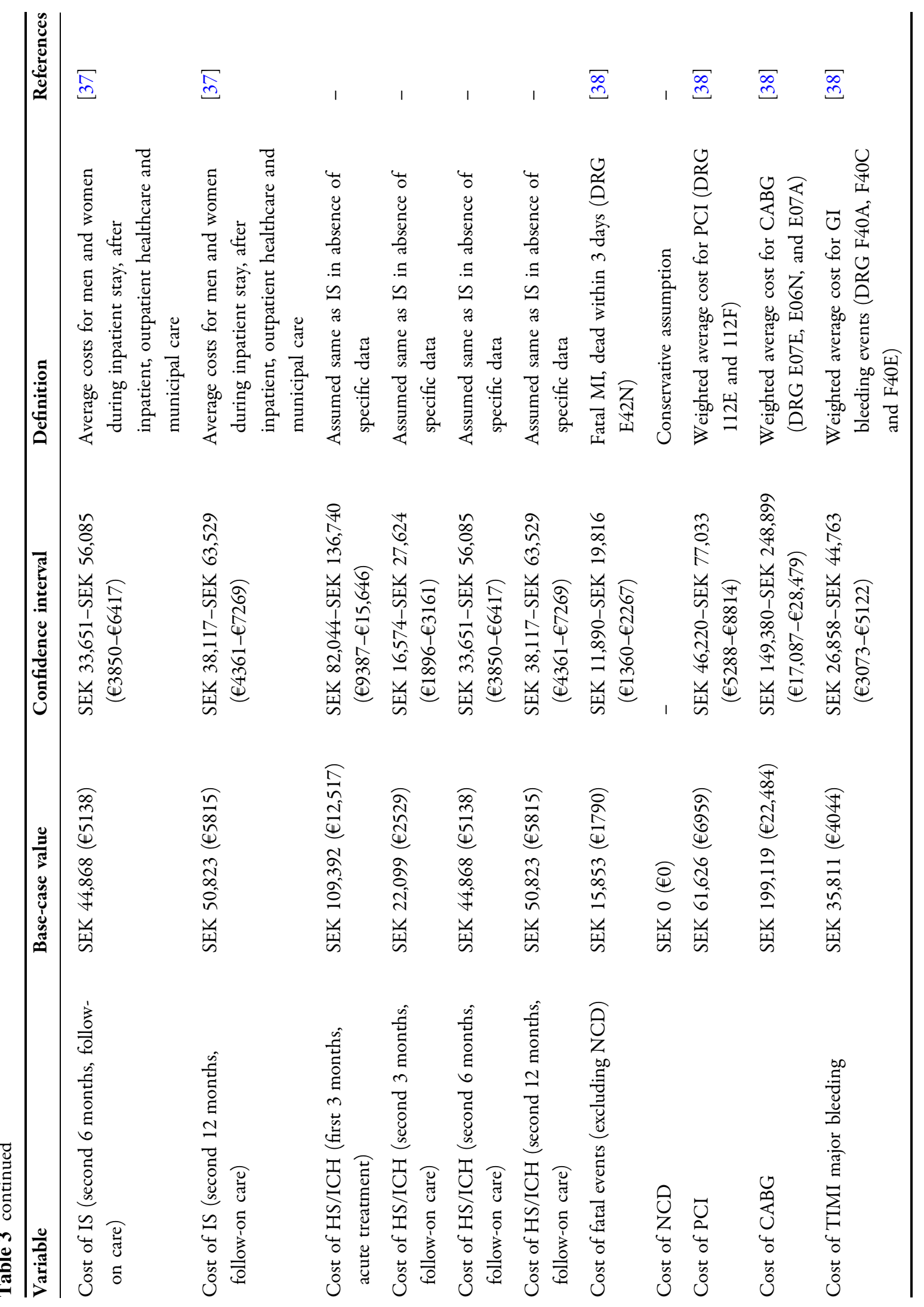




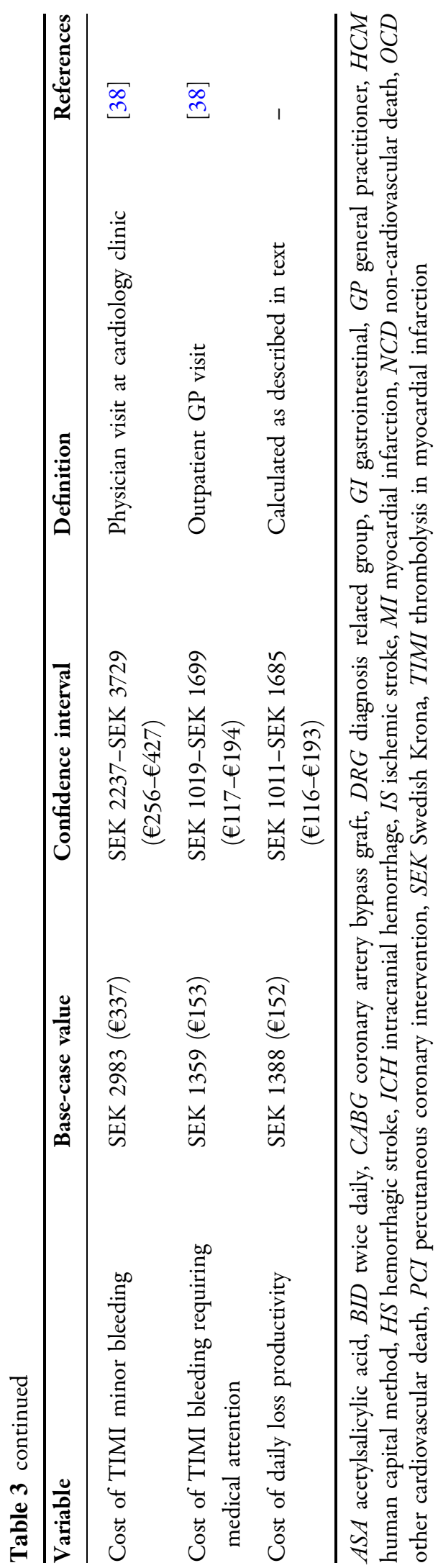

for consumption include health care, social services, education, general public consumption and private consumption [24]. The proportion of patients in each age category is representative of the ATLAS ACS 2-TIMI 51 trial.

\section{Utilities}

The ATLAS ACS 2-TIMI 51 trial was not optimally designed to measure utilities per health state, thus data from literature was considered more appropriate. The utility values for the non-fatal events of MI, IS and HS/ICH were taken from the Platelet inhibition and patient Outcomes (PLATO) trial [14]. This source was selected because it represents a recent source of utility estimates elicited from a large number of ACS patients. In addition, these utility values have been applied in many recent health technology appraisal submissions of treatment for ACS, and have been accepted as a robust source in those submissions. Utility values for stroke over time were not reported for the PLATO study. Hence, the best alternative source identified through the systemic literature review was used to estimate values for the second 6 months and later periods [41].

The lengths of disutility associated with bleeding and revascularization events were based on literature and expert opinion, and were assumed to be 30 days for TIMI major bleeding and PCI, 2 days for TIMI minor bleeding and TIMI bleeding requiring medical attention, and 84 days for CABG [15-17]. The proportion of patients suffering an event, multiplied by the respective disutility corrected for event-specific duration of quality of life impact, was deducted from the overall quality of life model outcomes. The utility values applied in the model are provided in Table 6. 
Table 4 Days of lost productivity

\begin{tabular}{|c|c|c|c|}
\hline Event & $\begin{array}{l}\text { Number of days of } \\
\text { productivity lost }\end{array}$ & $\begin{array}{l}\text { Confidence } \\
\text { interval }\end{array}$ & References \\
\hline MI & 80 & $60-100$ & Mean sick leave for an MI [25] \\
\hline IS & 137 & $103-171$ & Mean sick leave for a stroke $[25]$ \\
\hline $\mathrm{HS} / \mathrm{ICH}$ & 137 & $103-171$ & Assumed same as IS in absence of specific data \\
\hline PCI & 3 & $2-4$ & $\begin{array}{l}\text { Weighted average (DRG: E18C and E18E) of inpatient stay } \\
\text { after PCI [41] }\end{array}$ \\
\hline CABG & 8 & $6-10$ & $\begin{array}{l}\text { Weighted average (DRG: E07E, E06N and E07A) of } \\
\text { inpatient care after CABG [41] }\end{array}$ \\
\hline TIMI major bleed & 28 & $21-35$ & $\begin{array}{l}\text { Patients are recommended to take } 4 \text { weeks sick leave for } \\
\text { surgery of perforated peptic ulcer in accordance with the } \\
\text { assumption that major bleed is defined by a GI bleed [38] }\end{array}$ \\
\hline TIMI minor bleed & 0.5 & $0.4-0.6$ & $\begin{array}{l}\text { Assumption based on absence from work due to a healthcare } \\
\text { visit }\end{array}$ \\
\hline $\begin{array}{l}\text { TIMI bleed requiring } \\
\text { medical attention }\end{array}$ & 0.5 & $0.4-0.6$ & $\begin{array}{l}\text { Assumption based on absence from work due to a healthcare } \\
\text { visit }\end{array}$ \\
\hline
\end{tabular}

$C A B G$ coronary artery bypass graft, $D R G$ diagnosis related group, $G I$ gastrointestinal, $H S$ hemorrhagic stroke, $I C H$ intracranial hemorrhage, $I S$ ischemic stroke, $M I$ myocardial infarction, NCD non-cardiovascular death, $O C D$ other cardiovascular death, $P C I$ percutaneous coronary intervention, TIMI thrombolysis in myocardial infarction

Table 5 Inflated (SEK, 2013 values and $€, 2014$ conversion) cost of added life years adjusted to the ATLAS ACS 2-TIMI 51 trial age distributions [24]

\begin{tabular}{lllll}
\hline Age (years) & $\mathbf{5 0 - 6 4}$ & $\mathbf{6 5 - 7 4}$ & $\mathbf{7 5 - 8 4}$ & $\mathbf{2 8 5}$ \\
\hline $\begin{array}{l}\text { Consumption- } \\
\text { production }\end{array}$ & SEK $-15,382$ & SEK 21,969 & SEK 69,771 & SEK 147,683 \\
$(€-1737)$ & $(€ 2481)$ & $(€ 7878)$ & $(€ 16,676)$ \\
\hline
\end{tabular}

ATLAS ACS 2-TIMI 51 Anti-Xa Therapy to Lower Cardiovascular Events in Addition to Standard Therapy in Subjects with Acute Coronary Syndrome 2-Thrombolysis in Myocardial Infarction 51 (Clinicaltrials.gov identifier: NCT00809965), SEK Swedish Krona

\section{Analyses}

Costs and quality-adjusted life years (QALYs) were calculated over a 40-year (i.e., lifetime) horizon and were presented as mean outcome per patient allowing estimation of the incremental cost-effectiveness ratio (ICER). This approach is standard practice in Markov cohort modeling. An ICER below the assumed willingness-to-pay threshold of SEK 500,000
$(€ 56,458)$ was considered to demonstrate costeffectiveness.

A probabilistic sensitivity analysis (PSA) evaluated the uncertainty generated in the estimated ICERs by varying all model input parameters simultaneously for 10,000 iterations. Normal distributions were specified around the Weibull parameters in the model, all other parameters were assigned beta distributions. Univariate analyses varied one 
Table 6 Utilities applied in model per health state and for transient health states (representing the time since the event)

\begin{tabular}{|c|c|c|c|c|}
\hline Event & Utility & $\begin{array}{l}\text { Confidence } \\
\text { interval }\end{array}$ & Definition & References \\
\hline \multicolumn{5}{|l|}{ Health states } \\
\hline No event (event-free) & 0.842 & $0.632-1.000$ & No event & {$[14]$} \\
\hline MI first 6 months & 0.779 & $0.584-0.974$ & MI & [14] \\
\hline MI second 6 months & 0.821 & $0.616-1.000$ & Post-MI & [14] \\
\hline MI subsequent 6 month cycles & 0.821 & $0.616-1.000$ & Post-MI & [14] \\
\hline IS first 6 months & 0.703 & $0.527-0.879$ & Stroke & {$[14]$} \\
\hline IS second 6 months & 0.748 & $0.561-0.935$ & Post-stroke & {$[14,42]$} \\
\hline IS subsequent 6 month cycles & 0.792 & $0.594-0.990$ & Post-stroke & {$[14,42]$} \\
\hline $\mathrm{HS} / \mathrm{ICH}$ first 6 months & 0.703 & $0.527-0.879$ & $\begin{array}{l}\text { Assumed same as IS in absence of specific } \\
\text { data }\end{array}$ & - \\
\hline HS/ICH second 6 months & 0.748 & $0.561-0.935$ & $\begin{array}{l}\text { Assumed same as IS in absence of specific } \\
\text { data }\end{array}$ & - \\
\hline $\begin{array}{l}\mathrm{HS} / \mathrm{ICH} \text { subsequent } 6 \text { month } \\
\text { cycles }\end{array}$ & 0.792 & $0.594-0.990$ & $\begin{array}{l}\text { Assumed same as IS in absence of specific } \\
\text { data }\end{array}$ & - \\
\hline \multicolumn{5}{|l|}{ Transient health states } \\
\hline PCI & 0.792 & $0.594-0.990$ & PCI (30 days duration) & {$[17]$} \\
\hline CABG & 0.742 & $0.557-0.928$ & CABG (30 days duration) & {$[17]$} \\
\hline TIMI major bleeding & 0.750 & $0.563-0.938$ & GI bleeds ( 14 days duration) & {$[15]$} \\
\hline TIMI minor bleeding & 0.800 & $0.600-1.000$ & Minor bleeding ( 2 days duration) & {$[16]$} \\
\hline $\begin{array}{l}\text { TIMI bleed requiring medical } \\
\text { attention }\end{array}$ & 0.800 & $0.600-1.000$ & Minor bleeding ( 2 days duration) & {$[16]$} \\
\hline
\end{tabular}

$C A B G$ coronary artery bypass graft, $G I$ gastrointestinal, $H S$ hemorrhagic stroke, $I C H$ intracranial hemorrhage, $I S$ ischemic stroke, $M I$ myocardial infarction, $N C D$ non-cardiovascular death, $O C D$ other cardiovascular death, $P C I$ percutaneous coronary intervention, TIMI thrombolysis in myocardial infarction

model parameter at a time to investigate the impact of the upper and lower limits. The univariate analyses were categorized into nonefficacy-related and efficacy-related analyses. The non-efficacy-related analyses varied, for example, event costs and utility estimates. The efficacy-related analyses considered the difference in rates of MI, IS, HS/ICH and other $\mathrm{CV}$ death events between the rivaroxaban + STAPT and ST-APT alone arms. An uncertainty range of $\pm 25 \%$ was applied to all model inputs in the sensitivity analyses, with the exception of efficacy data (Fig. 3b), for which a regression analysis based on the results of the PSA was used to determine the upper and lower bounds of risk per event type (i.e., MI, IS, HS/ICH, CV death) when applying a 95\% confidence interval. Plus and minus $25 \%$ of the deterministic value offers in almost all cases a much wider interval than would be seen if the interval was based on 
published standard errors. The wider interval was chosen for the analyses because published standard errors often offer an unrealistic sense of confidence. For example, in a study by Bagust et al., a utility estimate is presented for ACS patients without secondary events of 0.842 , with a standard error of 0.002 [14]. While this may reflect the study sample from which the utility was derived, it does not necessarily represent the average quality of life of a patient from any other ACS population especially given dependency of quality of life on age and the size of the infarction, among other factors. Further scenarios assessed the model outcomes for unadjusted probabilities taken directly from the clinical trial (i.e., reflecting the clinical trial without manual adjustments to mimic Swedish clinical practice), assumed a 10-year modeling time horizon to remove uncertainty around assumptions far into the future, and applied zero costs (SEK 0 [€0]) to all treatments considered in the model. This latter scenario is designed to mimic a scenario driven by clinical efficacy and safety only.

\section{RESULTS}

\section{Base-Case Analysis}

The base-case cost-effectiveness results are summarized in Table 7. Based on the model, rivaroxaban $2.5 \mathrm{mg}$ BID given in combination with ST-APT was associated with a QALY gain of 0.14 and an incremental cost of SEK 10,000 (€1129), yielding a cost per QALY of SEK 71,246 (€8045) when compared with ST-APT alone. The results showed rivaroxaban $2.5 \mathrm{mg}$ BID to be associated with fewer non-fatal and fatal events (incremental costs of SEK $-1337(€-151)$ and SEK -226 (€-26) per patient, respectively). When analyzing only those patients in stratum 2 of the ATLAS trial (i.e., only including patients treated with clopidogrel or ticlopidine in addition to ASA, with or without

Table 7 Results of the base-case analysis (SEK, 2013 prices and $€, 2014$ conversion)

\begin{tabular}{|c|c|c|c|}
\hline & Rivaroxaban + ST-APT & ST-APT alone & Difference $(\Delta)$ \\
\hline \multicolumn{4}{|l|}{ Costs $^{\mathrm{a}}$} \\
\hline No event (treatment costs only) & SEK $164,478(€ 18,572)$ & SEK 154,969 (€17,498) & SEK $9509(€ 1074)$ \\
\hline Non-fatal events & SEK $374,756(€ 42,316)$ & SEK 376,093 (€42,467) & SEK $-1337(€-151)$ \\
\hline Fatal events & SEK $7082(€ 800)$ & SEK $7308(€ 825)$ & SEK $-226(€-26)$ \\
\hline Bleeding & SEK $1338(€ 151)$ & SEK $494(€ 56)$ & SEK 844 (€95) \\
\hline Revascularization & SEK 15,257 (€1723) & SEK 14,047 (€1586) & SEK $1210(€ 137)$ \\
\hline Total & SEK 562,911 $(€ 63,562)$ & SEK 552, $911(€ 64,433)$ & SEK $10,000(€ 1129)$ \\
\hline \multicolumn{4}{|l|}{ Effects } \\
\hline QALYs & 10.86 & 10.72 & 0.14 \\
\hline \multicolumn{4}{|l|}{ ICER } \\
\hline Costs per QALY & & & SEK 71,246 (€8045) \\
\hline
\end{tabular}

ICER incremental cost-effectiveness ratio, SEK Swedish Krona, ST-APT standard antiplatelet therapy, QALY qualityadjusted life year

a A 3.0\% discount rate was applied to all variables [22] 
rivaroxaban), the ICER is estimated at SEK $97,059(€ 11,105)$. When considering only those patients not treated with clopidogrel or ticlopidine (stratum 1 of the trial-ASA monotherapy, with or without rivaroxaban), the ICER reduces to SEK 31,149 (€3564). Rivaroxaban is estimated to be a cost-effective option for secondary prevention of cardiovascular events in ACS patients regardless of the standard of care currently being received by the patient (ASA monotherapy or ASA + clopidogrel or ticlopidine).

\section{Sensitivity analyses}

Uncertainty around the cost-effectiveness results was demonstrated by plotting simulations from the PSA on a costeffectiveness plane as presented in Fig. 2a. Almost all of the probabilistic simulations (92.6\%) suggest a QALY gain with rivaroxaban, with an associated increase in cost (upper righthand quadrant of the figure). The probability of rivaroxaban being cost-effective at a willingness-to-pay threshold of SEK 500,000 $(€ 56,458)$ is estimated to be $>99.9 \%$ (Fig. $2 b$ ).

Univariate sensitivity analyses were performed on all model variables and the results are presented in Fig. 3. The tornado graphs show that the base-case analysis was robust to plausible changes in the input parameters, with a majority of the parameters having minimal impact on the overall ICER (Fig. 3a). In the efficacy-related analysis (Fig. 3b), the results were most sensitive to changes in the difference of other $\mathrm{CV}$ death rates between the rivaroxaban $2.5 \mathrm{mg}$ BID + STAPT and ST-APT alone arms. This is not unexpected as there is a significant $\mathrm{CV}$ mortality benefit associated with rivaroxaban [11].
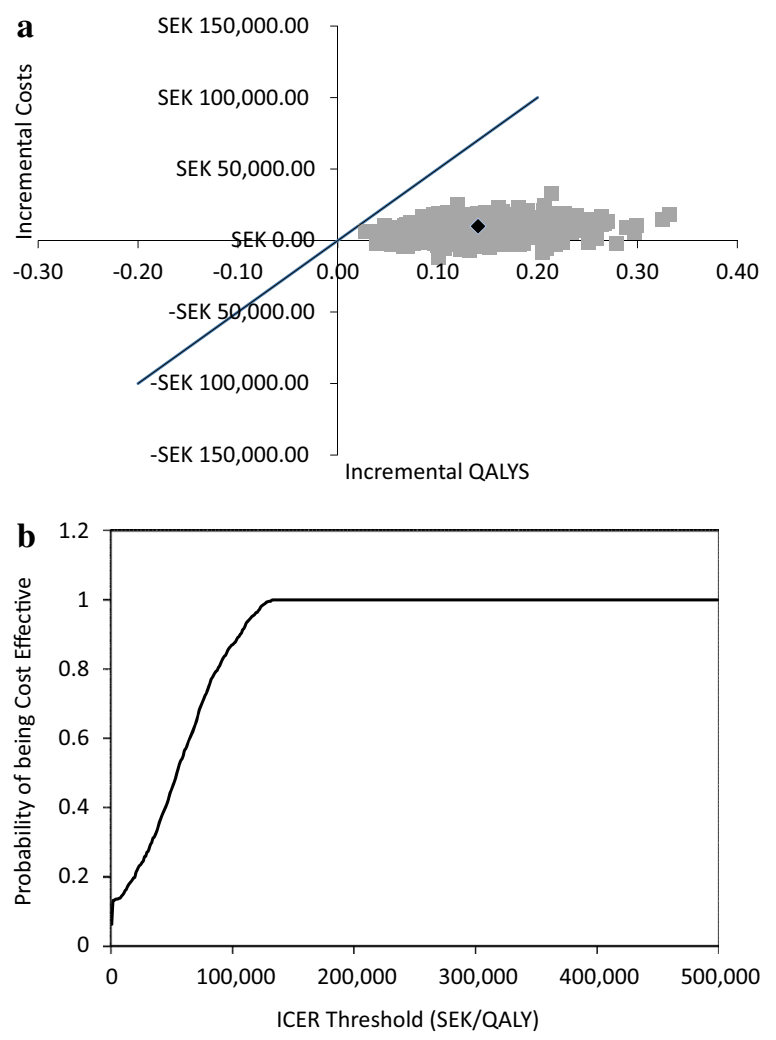

Fig. 2 Probabilistic sensitivity analyses (SEK, 2013 values and $€, 2014$ conversion): a scatterplot, $\mathbf{b}$ cost-effectiveness acceptability curve. ICER incremental cost-effectiveness ratio, $Q A L Y$ quality-adjusted life year, SEK Swedish Krona

Scenario analyses were run to further test the robustness of the model. Applying unadjusted probabilities directly from the clinical trial (not corrected for treatment discontinuations in the second year and not interpolated), resulted in a cost per QALY of SEK 63,855 (€7210).

Applying zero costs to all treatments in the model (rivaroxaban $2.5 \mathrm{mg}$ BID, clopidogrel/ ticlopidine and ASA), i.e., results are driven by efficacy alone, provided an ICER of SEK 3500 $(€ 395)$. Rivaroxaban generated slightly higher costs in this scenario, due to the increased risk of expensive stroke events with this treatment, partially outweighing the savings due to reductions in MIs and deaths. Additionally, 

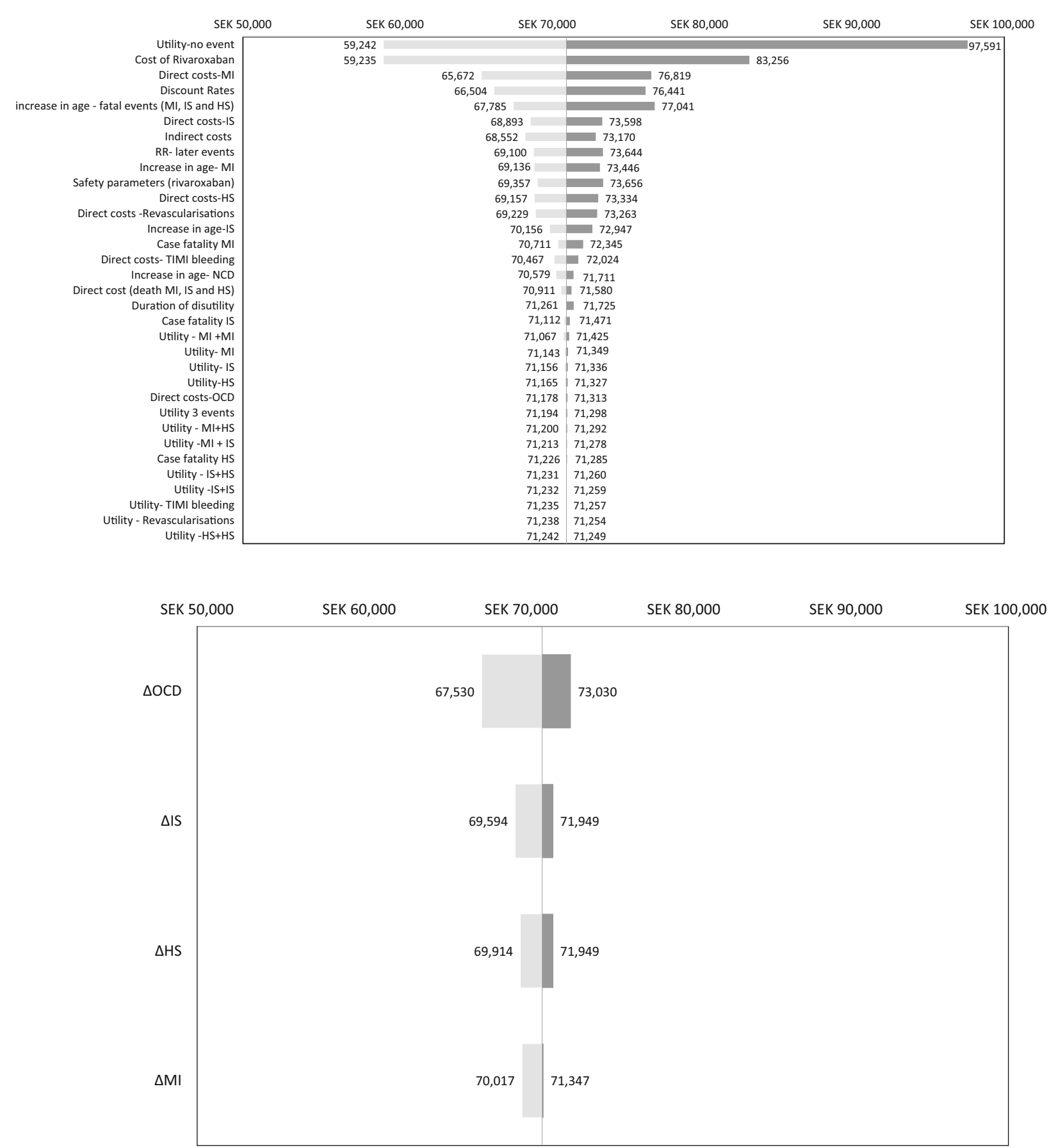

Fig. 3 Univariate sensitivity analyses (SEK, 2013 values and $€, 2014$ conversion): a non-efficacy-related input parameters, b efficacy-related input parameters. Costs in SEK are provided above each tornado plot. Equivalent costs in $€$ are provided below each tornado plot. $\Delta$ difference in,

rivaroxaban patients were more likely to experience more subsequent events because they lived longer, and the conservative
$H S$ hemorrhagic stroke, $I C H$ intracranial hemorrhage; $I S$ ischemic stroke, $M I$ myocardial infarction, NCD noncardiovascular death, $O C D$ other cardiovascular death, $S E K$ Swedish Krona, TIMI thrombolysis in myocardial infarction

estimate of a SEK 0 cost of non-CV death reduces the impact of the cost savings that would be gained with rivaroxaban. 
Assuming a 10-year model time horizon resulted in an ICER of SEK 83,111 (€9382). The ICER increased in this scenario because some of the long-term benefits of rivaroxaban therapy were not considered in the analysis.

Allowing the treatment effect to vary, reflecting the clinical trial (without adjustments), removing the cost disadvantage associated with rivaroxaban $2.5 \mathrm{mg}$ BID, and reducing the model time horizon did not alter conclusions of rivaroxaban $2.5 \mathrm{mg}$ BID in combination with ST-APT being considered a cost-effective treatment option.

\section{DISCUSSION}

The result from this study demonstrated that, from a Swedish societal perspective, rivaroxaban $2.5 \mathrm{mg}$ BID in combination with ST-APT can be considered a cost-effective treatment option for the secondary prevention of ACS in patients with elevated cardiac biomarkers without a prior history of stroke/ TIA. The base-case results are driven by the mortality benefit shown in the clinical data of rivaroxaban $2.5 \mathrm{mg}$ BID. It was observed in the clinical trial that rivaroxaban $2.5 \mathrm{mg}$ BID in combination with ST-APT reduced the occurrence of ACS events; the model demonstrated that the benefits in terms of life expectancy and QALY gain were maintained beyond the trial duration over a 40-year (i.e., lifetime) horizon, confirming the advantages of a dual-pathway strategy in patients with elevated cardiac biomarkers without a prior history of stroke/TIA in the secondary prevention of ACS. Sensitivity analyses were conducted to test the impact of key assumptions. The ICER remained within widely accepted cost-effectiveness thresholds in these analyses.
This is the first published cost-effectiveness analysis of rivaroxaban $2.5 \mathrm{mg}$ BID for secondary prevention of ACS. This model demonstrated several improvements compared to previous ACS models used to estimate the costeffectiveness of other antithrombotic therapies [14-17]. The model was able to capture both single and multiple ACS events, as well as revascularization procedures. This captured the full picture of secondary event care in ACS patients. In addition, IS and $\mathrm{HS} / \mathrm{ICH}$ were differentiated, as were fatal and non-fatal events, thus allowing more accurate estimation of costs in the model. The model was developed and calibrated to reflect disease progression in ACS patients as accurately as possible. Calibration to life expectancy after a first MI ensured that the survival following a first MI predicted by the model was reflective of post-MI survival as observed in reality. Increased risks of events due to age and/or the occurrence of earlier events were also explicitly captured in the model structure.

Many of the model inputs were derived from Swedish databases, reflecting the perspective of this study. All of the databases utilized for this research are national databases and are owned by Swedish national authorities. The data held are based on the entire Swedish population and their coverage is generally considered to be high. As such, these databases are considered as strong representations of the population of interest. Furthermore, the databases have existed for decades and the data held within them is widely regarded to be of high quality. To best reflect the current situation in Sweden, the most recent data from each database were used, with at least one data year included to ensure robustness of model inputs.

However, the approach presented here is not without its limitations. The model provides a simplification of what is expected in reality. Long-term outcomes believed to reflect the 
consequences of therapy in ACS patients were based on a number of assumptions to capture natural disease progression. Treatment durations of 2 years for rivaroxaban and 1 year for clopidogrel or ticlopidine were assumed to reflect ESC guidelines [7, 8]; a RRR from the CURE trial [29] was applied to both treatment arms to adjust for the removal of clopidogrel or ticlopidine treatment effect after 1 year. Manual adjustments to discontinuation rates in the rivaroxaban arm were required for the second year of treatment to ensure alignment with expectations on the use of rivaroxaban in clinical practice. There is currently no data available on the real-life use of rivaroxaban in this patient population. As such, the discontinuation adjustments applied in the evaluation are based on expert opinion. Further, the model does not consider the longterm impact of non-fatal/non-ICH bleeding events beyond the duration of treatment as this was believed to have marginal impact on the overall model outcomes. In the absence of specific HS/ICH estimates, the costs and utilities applied to patients experiencing IS were also applied to those with HS/ICH.

\section{CONCLUSION}

The analysis suggests that rivaroxaban $2.5 \mathrm{mg}$ BID provides a cost-effective treatment strategy in a Swedish societal setting for the secondary prevention of ACS in patients with elevated biomarkers without prior stroke/TIA, mainly driven by a benefit in terms of reduced mortality as demonstrated in the ATLAS ACS 2-TIMI 51 trial. This analysis may help to support the combination of ST-APT and rivaroxaban $2.5 \mathrm{mg}$ BID for the secondary prevention of ACS events, as recommended by the ESC STEMI guidelines in patients with low bleeding risk [8]. The conclusion of cost- effectiveness holds, regardless of the standard of care currently being received by the patient (ASA monotherapy or ASA + clopidogrel or ticlopidine).

\section{ACKNOWLEDGMENTS}

Sponsorship for this study and article processing charges were funded by Bayer Pharma AG. All authors had full access to all the data in this study and take complete responsibility for the accuracy of the data analysis. All named authors meet the International Committee of Medical Journal Editors (ICMJE) criteria for authorship for this manuscript, take responsibility for the integrity of the work as a whole, and have given final approval to the version to be published.

Conflict of interest. Najida Begum was an employee of Pharmerit at the time of the study. Pharmerit was financed by Bayer Pharma AG to complete this study. Stephanie Stephens is an employee of Pharmerit. Olaf Schoeman was an employee of Bayer Pharma AG at the time of the study and is now an employee of Pharmerit. Anina Fraschke is an employee of Bayer Pharma AG. Bodo Kirsch is an employee of Bayer Pharma AG. Jean-Baptiste Briere is an employee of Bayer Pharma AG. Freek W. A. Verheugt has received honoraria for speaker fees and consultancy from AstraZeneca, Bayer Pharma AG, Boehringer-Ingelheim, BMS/Pfizer and Daiichi-Sankyo. Ben A. van Hout is an owner and employee of Pharmerit.

Compliance with ethics guidelines. The analysis in this article is based on previously conducted studies and does not involve any new studies of human or animal subjects performed by any of the authors. 
Open Access. This article is distributed under the terms of the Creative Commons Attribution Noncommercial License which permits any noncommercial use, distribution, and reproduction in any medium, provided the original author(s) and the source are credited.

\section{REFERENCES}

1. World Health Organization. The top 10 causes of death 2000 and 2012. http://www.who.int/ mediacentre/factsheets/fs310/en/. Accessed Apr 30, 2015.

2. WHO. The Global Burden of Disease 2004 Update. Geneva: World Health Organization; 2008. http:// www.who.int/healthinfo/global_burden_disease/GB D_report_2004update_full.pdf?ua=1. Accessed Apr $30,2015$.

3. Jernberg T, Held C, Rydberg E, et al. SWEDEHEART Annual report 2014. Stockholm: Tomas Jernberg, Karolinska University Hospital; 2014. http://www. ucr.uu.se/swedeheart/index.php/dokument-sh/arsr apporter. Accessed Apr 30, 2015.

4. Rosvall M, Ohlsson H, Hansen O, Chaix B, Merlo J. Auditing patient registration in the Swedish quality register for acute coronary syndrome. Scand J Public Health. 2010;38(5):533-40.

5. Hamm CW, Möllmann H, Bassand J-P, van de Werf F. Acute coronary syndromes. In: Camm AJ, Lüscher TF, Serruys PW, editors. The ESC textbook of cardiovascular medicine. 2nd ed. Oxford: Oxford University Press; 2009.

6. Kumar A, Cannon CP. Acute coronary syndromes: diagnosis and management, part I. Mayo Clin Proc. 2009;84(10):917-38.

7. Hamm CW, Bassand J-P, Agewall S, et al. ESC Guidelines for the management of acute coronary syndromes in patients presenting without persistent ST-segment elevation: the Task Force for the management of acute coronary syndromes (ACS) in patients presenting without persistent STsegment elevation of the European Society of Cardiology. Eur Heart J. 2011;32(23):2999-3054.

8. Task Force on the management of ST-segment elevation acute myocardial infarction of the European Society of Cardiology (ESC), Steg PG, James SK, Atar D, et al. ESC Guidelines for the management of acute myocardial infarction in patients presenting with ST-segment elevation. Eur Heart J. 2012;33(20):2569-619.

9. Fox KA, Carruthers KF, Dunbar DR, et al. Underestimated and under-recognized: the late consequences of acute coronary syndrome (GRACE UK-Belgian Study). Eur Heart J. 2010;31(22):2755-64.

10. Bayer Pharma AG Thrombosis Advisor: A venous and arterial thrombosis resource for physicians. http:// www.thrombosisadviser.com/en/acs/investigationalstrategies/. Accessed Apr 30, 2015.

11. Mega JL, Braunwald E, Wiviott SD, et al. Rivaroxaban in patients with a recent acute coronary syndrome. N Engl J Med. 2012;366(1):9-19.

12. Centre for Reviews and Dissemination. CRD's guidance for undertaking reviews in health care. York: CRD; 2008. https://www.york.ac.uk/media/ crd/Systematic_Reviews.pdf. Accessed Apr 30, 2015.

13. National Institute for Health and Care Excellence. Rivaroxaban for preventing adverse outcomes after acute management of acute coronary syndrome. London: NICE; 2015. https:// www.nice.org.uk/guidance/indevelopment/gid-tag 316/documents. Accessed Apr 30, 2015.

14. Bagust A, Boland A, Blundell $\mathrm{M}$, et al. Liverpool Reviews and Implementation Group (LRiG). Ticagrelor for the treatment of acute coronary syndromes. Liverpool: The University of Liverpool; 2011. http://www.nice.org.uk/guidance/ta236/doc uments/acute-coronary-syndromes-ticagrelor-evide nce-review-group-report2. Accessed Apr 30, 2015.

15. Crespin DJ, Federspiel JJ, Biddle AK, Jonas DE, Rossi JS. Ticagrelor versus genotype-driven antiplatelet therapy for secondary prevention after acute coronary syndrome: a cost-effectiveness analysis. Value Health. 2011;14(4):483-91.

16. Sullivan PW, Arant TW, Ellis SL, Ulrich H. The cost effectiveness of anticoagulation management services for patients with atrial fibrillation and at high risk of stroke in the US. Pharmacoeconomics. 2006;24(10):1021-33.

17. Latour-Pérez J, de Miguel Balsa E, Betegón L, Badia $\mathrm{X}$. Using triple antiplatelet therapy in patients with non-ST elevation acute coronary syndrome managed invasively: a cost-effectiveness analysis. Value Health. 2008;11(5):853-61.

18. Wallentin L, Becker RC, Budaj A, et al. Ticagrelor versus clopidogrel in patients with acute coronary syndromes. N Engl J Med. 2009;361(11):1045-57. 
19. Wiviott SD, Braunwald E, McCabe $\mathrm{CH}$, et al. Prasugrel versus clopidogrel in patients with acute coronary syndromes. $\mathrm{N}$ Engl J Med. 2007;357(20):2001-15.

20. Mega JL, Braunwald E, Murphy S, et al. Rivaroxaban in patients after an acute coronary syndrome with cardiac biomarker elevation: insights from the ATLAS ACS 2-TIMI 51 Trial. Eur Heart J. 2014;35(Suppl 1):992.

21. Heeg B, Damen J, van Hout B. Oral antiplatelet therapy in secondary prevention of cardiovascular events: an assessment from the payer's perspective. Pharmacoeconomics. 2007;25(12):1063-82.

22. Pharmaceutical Benefits Board Sweden. Changes to the general guidelines for economic evaluations from the Pharmaceutical Benefits Board LFNAR 2003:2 (TLVAR 2015:1); 2015. http://www.tlv.se/ Upload/Lagar_och_foreskrifter/TLVAR_2015_1.pdf Accessed May 15, 2015.

23. Statistiska centralbyrån. Konsumentprisindex $(1980=100)$, fastställda tal. http://www.scb.se/ sv_/Hitta-statistik/Statistik-efter-amne/Priser-och-ko nsumtion/Konsumentprisindex/Konsumentprisind ex-KPI/33772/33779/Konsumentprisindex-KPI/2721 51/. Accessed Nov 22, 2013.

24. Ekman M. Consumption and production age in Sweden: basic facts and health economic implications. Dissertation for the degree of Doctor of Philosophy at the Stockholm School of Economics; 2002.

25. Försäkringskassan. Beslutsstödet: Sjukskrivningsm önster före och efter införandet av försäkringsmed icinska rekommendationer för fysiska sjukdomar. Socialförsäkringsrapport 2009;5. https://www.forsak ringskassan.se/wps/wcm/connect/6043de6a-abf1-44a c-a48d-a92eb438a50d/socialforsakringsrapport_2009 _5.pdf?MOD=AJPERES. Accessed Apr 30, 2015.

26. Skatteverket. Arbetsgivaravgifternas sammansättni ng; 2011. http://www.skatteverket.se/foretagorganis ationer/arbetsgivare/socialavgifter/arbetsgivaravgift er.4.233f91f71260075abe8800020817.html. Accessed Nov 22, 2013.

27. Statistiska centralbyrån. Genomsnittlig månadslön efter sektor 1992-2011: Samtliga sektorer: 2011. http://www.scb.se/sv_/Hitta-statistik/Statistik-efteramne/Arbetsmarknad/Loner-och-arbetskostnader/L onestrukturstatistik-hela-ekonomin/14367/14374/ 149087/. Accessed Nov 22, 2013.

28. European Central Bank. Eurosystem. Euro foreign exchange reference rates. http://www.ecb.europa. $\mathrm{eu} /$ stats/exchange/eurofxref/html/eurofxref-graphsek.en.html. Accessed Jan 3, 2014.
29. Yusuf S, Zhao F, Mehta SR, Chrolavicius S, Tognoni G, Fox KK, Clopidogrel in Unstable Angina to Prevent Recurrent Events Trial Investigators. Effects of clopidogrel in addition to aspirin in patients with acute coronary syndromes without ST-segment elevation. $\mathrm{N}$ Engl J Med. 2001;385(7):494-502.

30. Socialstyrelsen. Statistikdatabas för diagnoser i sluten vård. http://www.socialstyrelsen.se/statistik/ statistikdatabas/diagnoserislutenvard. Accessed Nov 22, 2013.

31. Official Statistics of Sweden. Life tables for 2010, divided into men and women. http://www.scb.se/ Statistik/BE/BE0101/2013A02F/Be0101Livsl\%C3\% A4ngdstabeller_13_eng.xls. Accessed Nov 14, 2013.

32. van de Werf F, Bax J, Betriu A, et al. ESC Committee for Practice Guidelines (CPG). Management of acute myocardial infarction in patients presenting with persistent ST-segment elevation: the Task Force on the Management of ST-Segment Elevation Acute Myocardial Infarction of the European Society of Cardiology. Eur Heart J. 2008;29(23):2909-45.

33. Smolina K, Wright FL, Rayner M, Goldacre MJ. Long-term survival and recurrence after acute myocardial infarction in England, 2004 to 2010. Circ Cardiovasc Qual Outcomes. 2012;5(4):532-40.

34. Socialstyrelsen. Dödsorsaksstatistik. http://www. socialstyrelsen.se/statistik/statistikefteramne/dodso rsaker. Accessed Nov 14, 2013.

35. Isaksson R, Jansson J, Lundblad D, et al. Better longterm survival in young and middle aged women than in men after a first myocardial infarction between 1985 and 2006. An analysis of 8,630 patients in the Northern Sweden MONICA study. BMC Cardiovasc Disord 2011;11(1):1-8.

36. Sigvant B, Henriksson M, Lundin F, Wahlberg E. Asymptomatic peripheral arterial disease: is pharmacological prevention of cardiovascular risk cost-effective? Eur J Cardiovasc Prev Rehabil. $2011 ; 18(2): 254-61$.

37. Ghatnekar O, Steen Carlsson K. Kostnader för insjuknande i stroke år 2009. En incidensbaserad studie. Lund: IHE; 2012.

38. Socialstyrelsen. Nationella vikter för slutenvårdsgru pper, NordDRG CC-versionen 2013. http://www. socialstyrelsen.se/klassificeringochkoder/norddrg/v ikter. Accessed Nov 22, 2013.

39. TLV. Läkemedel. http://www.tlv.se/beslut/sok/ lakemedel/. Accessed Feb 13, 2013. 
40. Olofsson G. Age, work and retirement in Swedenviews, policies and strategies of key actors: an overview of work pensions and early exit as well as state policies and employer strategies towards the older workforce. Background paper on the Swedish case for the 'Millennium Project' conference in Tokyo. Tokyo: Japanese Institute of Labour; 2001.
41. Socialstyrelsen. Statistikdatabasen för diagnoser i sluten vård. http://192.137.163.49/sdb/par/val. aspx. Accessed Oct 25, 2012.

42. Ara R, Brazier JE. Populating an economic model with health state utility values: moving toward better practice. Value Health. 2010;13(5):509-18. 